\title{
A Study on Thermo-Mechanical Analysis of Hot Rolling \& Estimation of Residual Stresses by using FEM
}

\author{
Santosh Kumar ${ }^{1}$, Prof.Bharat S Kodli ${ }^{2}$ \\ ${ }^{1}$ Mechanical Engineering Department, PDA College of Engineering, Gulbarga, Karnataka, India \\ ${ }^{2}$ Mechanical Engineering Department, PDA College of Engineering, Gulbarga, Karnataka, India 585102
}

\begin{abstract}
The major problem in rolling process is the defects like fire cracks, severe sticking in a billet mill, and etc. This paper deals with the study on reducing or minimizing the defects of rolling process. The analysis has been carried out for different temperature i.e. $100^{\circ} \mathrm{C}, 150^{\circ} \mathrm{C}, 200^{\circ} \mathrm{C}, 250^{\circ} \mathrm{C}$. As the temperature goes on increasing correspondingly the residual stresses decreases. Hot rolling process helps in reduced residual stresses at high temperature \& helps in formation of smooth granular structure of product. Due to the symmetry of the rolling components, half the model is built \& the analysis is carried out with 4 roller sizes varying from $8 \mathrm{~mm}$ to $20 \mathrm{~mm}$ with $4 \mathrm{~mm}$ increment \& the results were tabulated by using ANSYS. This will helps in estimation of residual stresses.
\end{abstract}

Keywords: Rolling process, Residual Stresses, FEM etc

\section{INTRODUCTION}

In the manufacturing process based on numerical standards, simulation is an important tool in applying the experience and know-how gained in the past to the development of new models. A limiting factor in design process is the necessity of producing the desired shape in a rolling process, for example, with no cracks or wrinkles in the sheet metal. As automotive and aerospace industries are growing rapidly the demand for precise and accurate information concerning parts design and formability of metal sheet becomes essential. Sheet metal forming simulation plays an indispensable role in integrating manufacturing necessities into the product design process at an early stage. In conjunction with concurrent engineering, sheet metal forming simulation is proving to be an important tool in linking design and manufacturing. Since sheet metals are most susceptible to failure under plane strain condition, several plane strain membrane finite element codes for sheet metal forming analysis has been developed by M. J. Saran and Wagoner, W. H. Frey and Wenner, M. P. Sklad . These codes, in the absence of shape tooling curvatures, are capable of predicting deformation strains very accurately, but as tooling curvature becomes larger to cause significant bending strains, these codes can no longer capable to predict accurately. The objects of this works will focus on simulating nonlinear sheet forming process using finite element technique in order to come up with a clear and better understanding of metal flow of sheet metal forming process.

\section{Problem Statement:}

From the Literature survey it has been observed that simulation of all the parameters in details \& estimation of residual stresses in hot rolling process is difficult by following experimental \& numerical methods:

* Boring-out method

* Hole drilling method

* Sectioning method.

These methods require expensive equipment, these are highly sensitive to microstructure properties \& some of these are destructive methods. And it is difficult to predict the effects caused by changes in constituent materials, dimensions, cooling rates, etc.The rolling process is very important in automobile, aerospace industries to get the proper shape $\&$ defect free objects.

\section{Experimental Procedure}

The analysis for rolling is carried out in two stages using nonlinear material and geometrical domain. Initially the boundary conditions are applied using symmetrical boundary conditions are the bottom and displacement boundary conditions to the left side geometry for $2 \mathrm{~mm}$. The solver options are set for proper convergence in the problem. More number of steps is given with reduction of penetration tolerance settings. The analysis is done for the following cases.

- The analysis is carried out to find the effect of roller size on the stress formation

- Finding the effect of rolling on residual stress formation 
In both the cases, the results for deflections, stresses, plastic strains and contact pressure are captured. Plastic strain and contact pressure are the main parameters for rolling simulation for finding error free rolled parts.

\subsection{Temperature effects on rolling process \\ When temperature is $150^{\circ} \mathrm{C}$}

Temperature plays important role in structural safety of the problem. Molecular structure will change with the increase of temperature. All properties like yield stress, young's modulus, thermal conductivity, specific heat, thermal expansion coefficient will change with the temperature. Hot rolling operation helps in reduced residual stress formation and at high temperature recrystallization helps in smooth granular formation in the final product helps in better products.

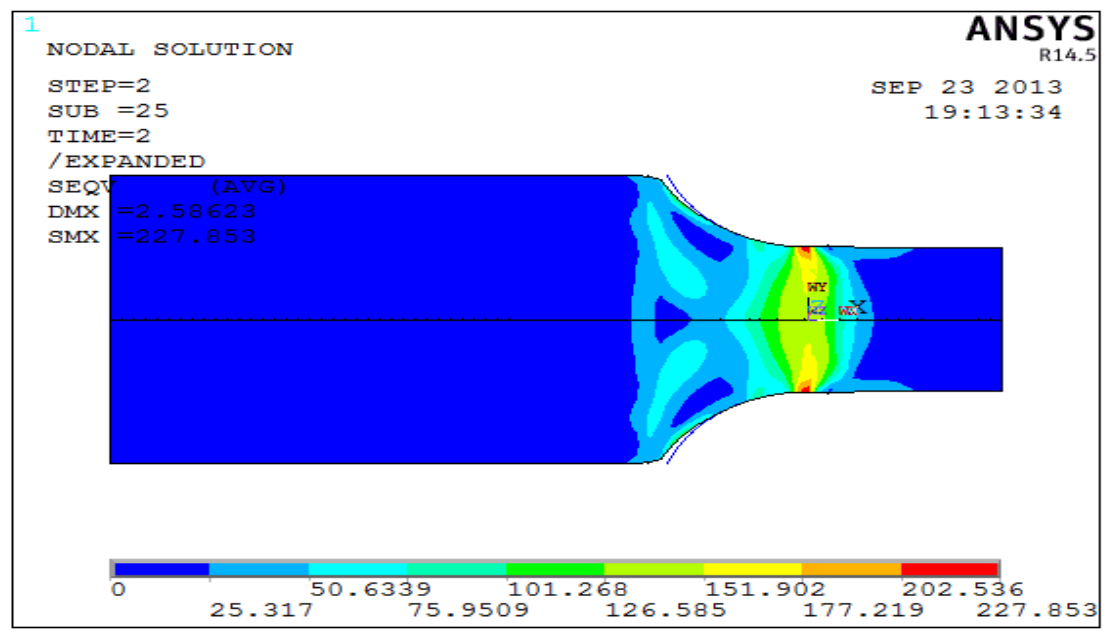

Fig1: Residual Stress in the rolled material

The figure1 shows maximum residual stress of $227.853 \mathrm{Mpa}$ with $150{ }^{0} \mathrm{C}$ temperature given for the rolled material. The stress reduction can be mainly attributed to reduced yield stress due to temperature effects.

\section{When temperature is $200^{\circ} \mathrm{C}$}

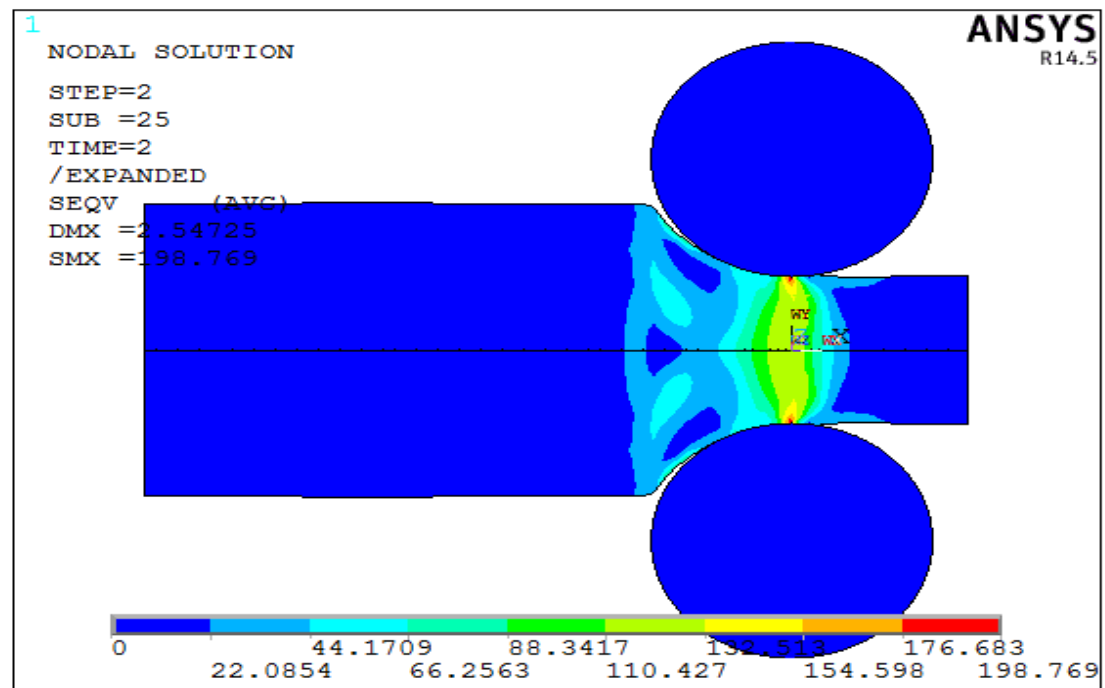

Fig2 Residual stress at $200{ }^{\circ} \mathrm{c}$

The figure 2 shows reduced residual stress with increase in temperature from 100 degrees to 200 degrees. The stress value drop can be attributed mainly to reduced yield stress along with young's modulus values. 
When temperature is $250^{\circ} \mathrm{C}$

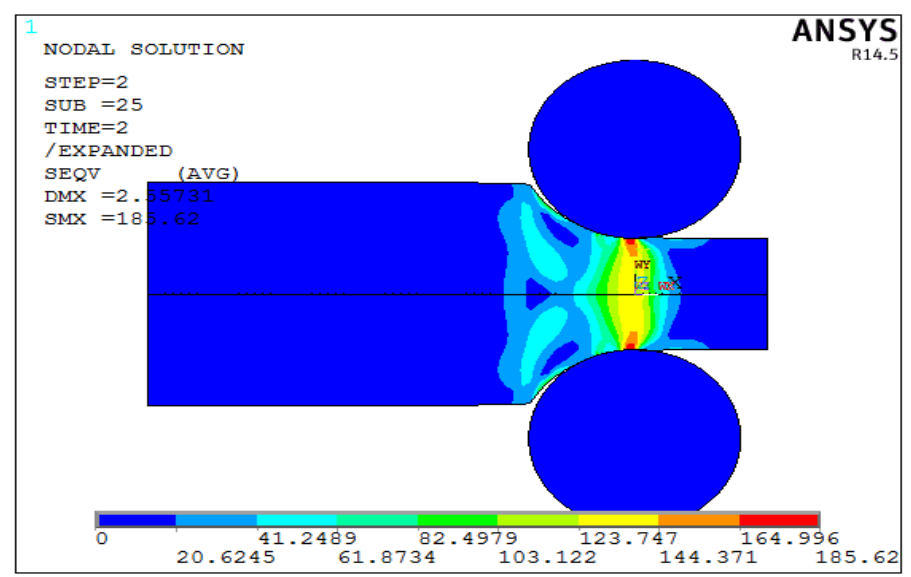

Fig 3: Residual stress formation at $250^{0}$ degree centigrade

The figure 3 shows residual stress under thermal environment. Maximum residual stress is dropped to $185.62 \mathrm{Mpa}$ with the increase in the temperature loads. This drop also mainly attributed to reduced young's modulus and yield strength which are functions of temperature.

Table 1: Temperature effect on Residual Stress formation

\begin{tabular}{|l|l|}
\hline Temperature (degrees) & Residual Stress (Mpa) \\
\hline 100 & 277 \\
\hline 150 & 227 \\
\hline 200 & 198 \\
\hline 250 & 185 \\
\hline
\end{tabular}

\subsection{Effect of roller diameters}

\section{Diameter of roller $12 \mathrm{~mm}$ :}

Analysis has been carried out by changing the roller diameter to $12 \mathrm{~mm}$. The effect of roller diameter on the stress and strain formation is analysed. The results are as follows.

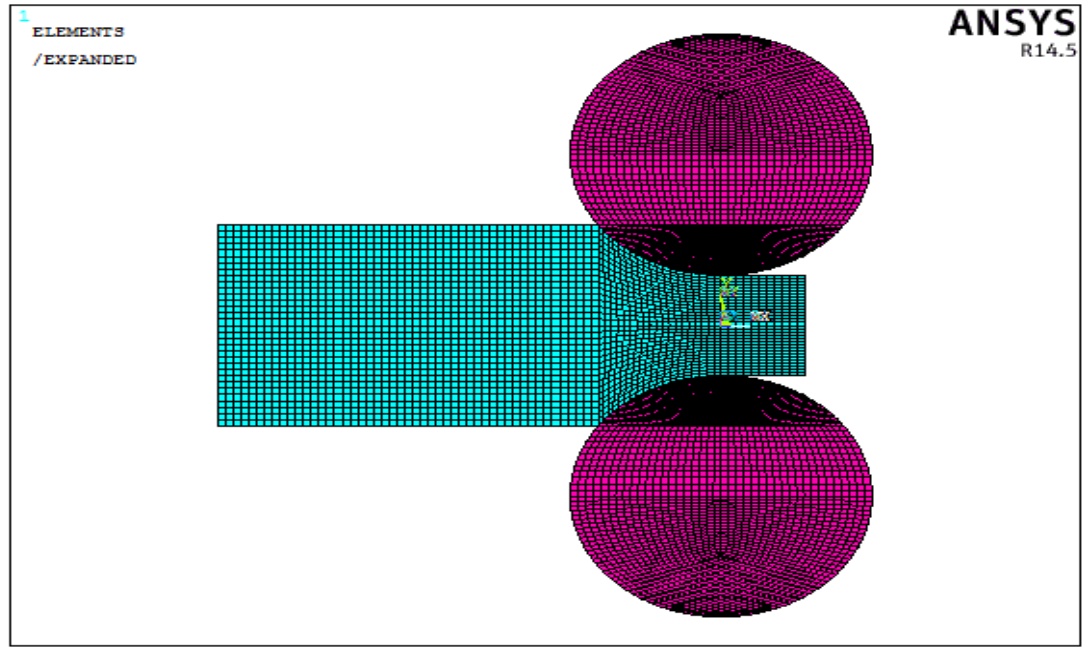

Fig4.14: Element Plot (Roller Diameter 12mm)

The figure4.14 shows mesh for the increased diameter of the roller structure. Again plane stress with thickness option is considered to solve the problem. Now the roller diameter is increased to $12 \mathrm{~mm}$. same output thickness is maintained for the sheet metal. A total of 8421 elements with 4032 Nodes. Plane 182 element with large deformation capacity is used for meshing. Contact pairs are created between roller materials with sheet metal. 


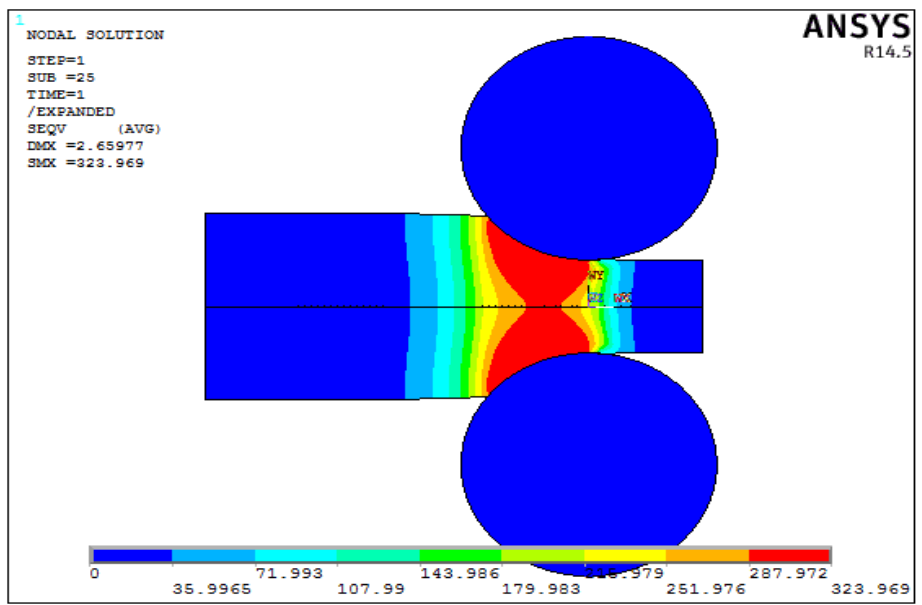

Fig4.15Vonmises Stress Plot (Roller Diameter 12mm)

The figure4.15 shows developed vonmises stress of 323.969Mpa as shown with red colour. Maximum stress colour is represented by red colour. The various colours at the status bar represents variation of stress values. The spread is observed to be almost parabolic with the rolling process. This stress is residual stress which will retain after the plastic deformation.

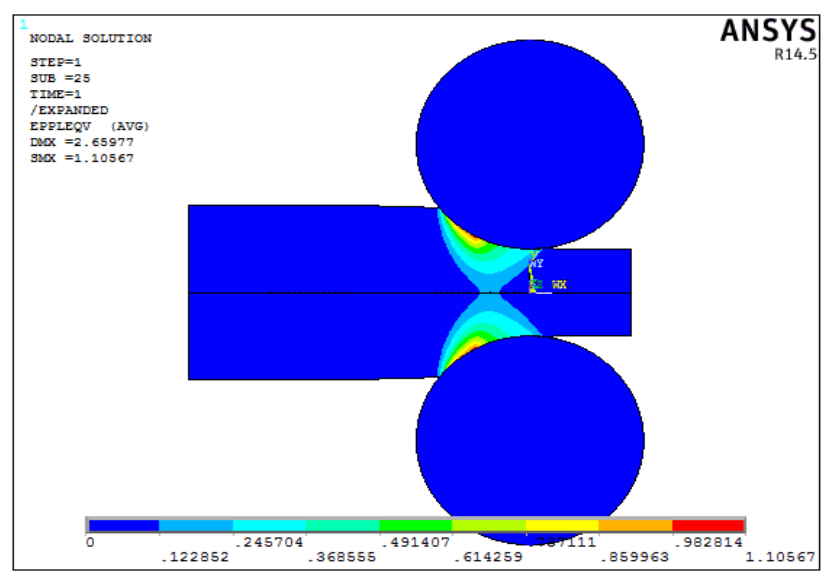

Fig4.16: Plastic Strain Plot (Roller Diameter 12mm)

The figure4.16 shows plastic strain development in the structure. Maximum plastic strain is around 1.10567. The maximum plastic region strain is represented by red colour zone. The strain in the other region away from the rolling region is less.

\section{Diameter of roller $16 \mathrm{~mm}$ :}

Further analysis is carried out $16 \mathrm{~mm}$ diameter roller. The geometry is rebuilt and meshed with plane 182 elements having large deformation effects. The mesh is refined at the rolling region. The results are as follows.

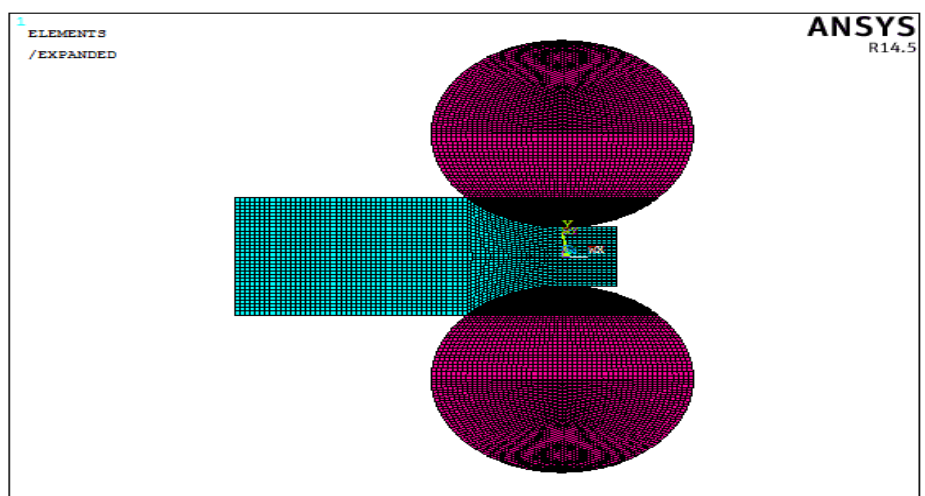

Fig4.20: Element Plot (Roller Diameter 16mm) 
The figure4.20 shows dense mesh in the region of rolling process. Higher density of mesh helps in estimating the proper stress in the region. Contact pairs are created after selecting the contacting line regions. Target and contact elements are created through contact manager option. Due to symmetry of the problem, half geometry is built and meshed. Nonlinear material properties are applied using nonlinear domain. The roller is meshed with high rigid material properties.

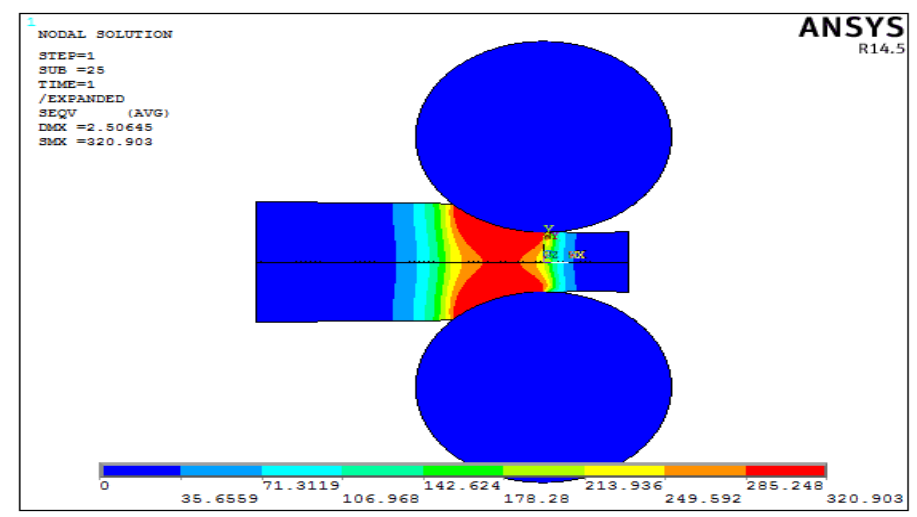

Fig4.21; vonmises Stress Plot

The figure4.21 shows developed vonmises stress of 320.9 Mpa. Maximum stress is spread in the region of rolling. Stresses are observed to be less away from the stress concentration regions.

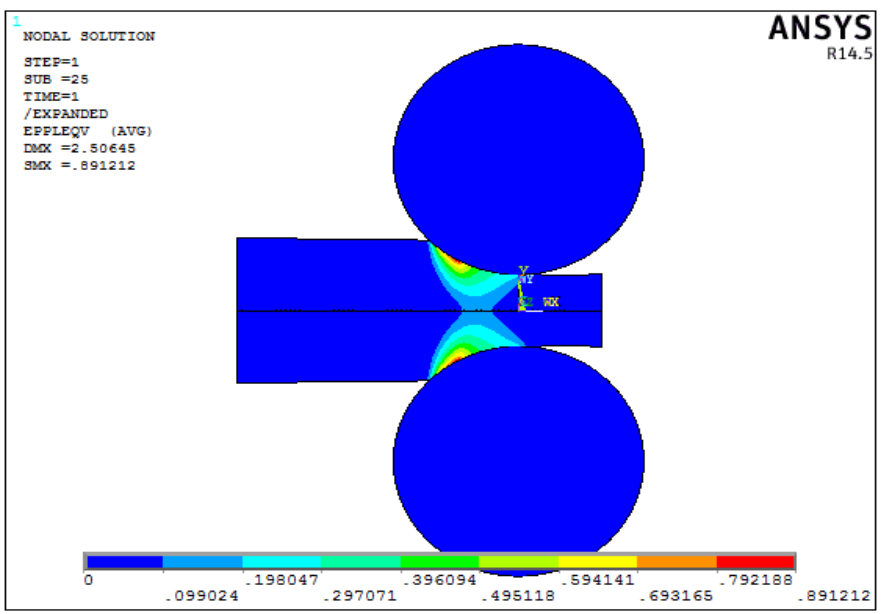

Fig4.22: Plastic Strain Plot

The figure4.22 shows plastic strain in the member. Maximum plastic strain is around 0.891 as shown in the figure. The region of plastic strain is maximum concentrated around the rolling region.

\section{Diameter of roller 20mm:}

Final analysis is carried out with $20 \mathrm{~mm}$ diameter roller. The results are as follows.

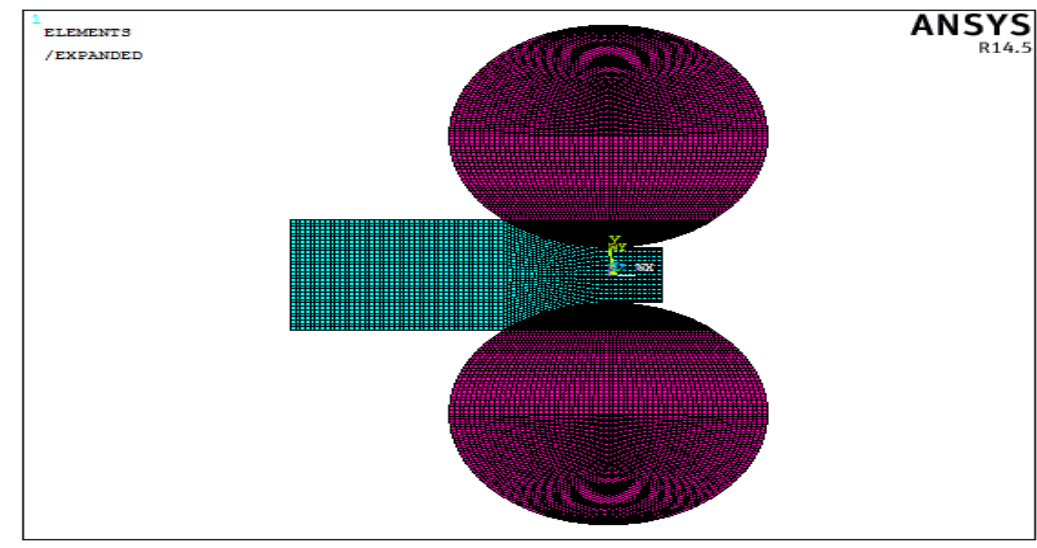

Fig4.26: Meshed Plot (Diameter of the roller 20mm) 
The figure4.26 shows meshed plot of the problem. Plane182 element with thickness option is used for solving the problem. Dense mesh is created at the rolling region. Symmetry option is used for faster solution. Also load can be estimated with faster convergence rate. For all the load cases, the rolling length is fixed for $2 \mathrm{~mm}$. The rollers are fixed in position and displacement convergence is considered for the problem.

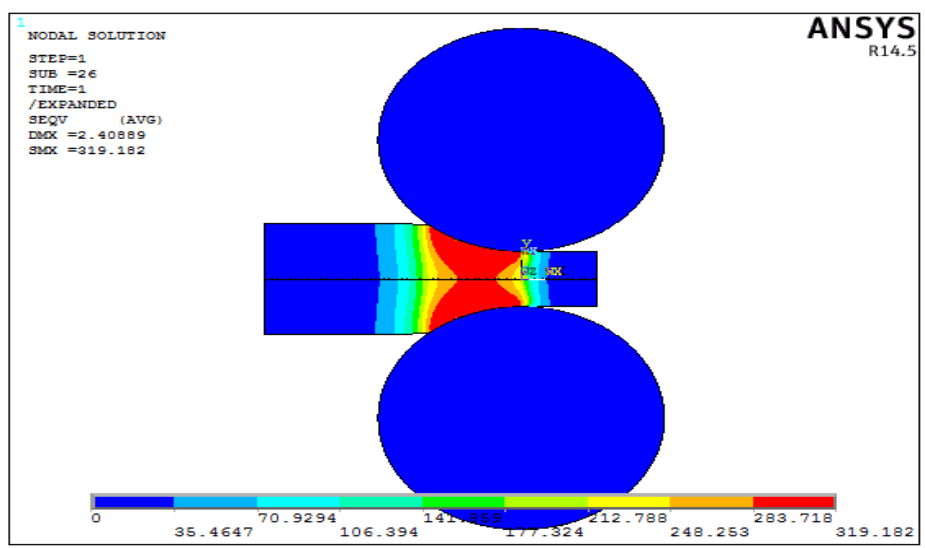

Fig4.27: vonmises Stress Plot (Maximum vonmises stress 319.182Mpa)

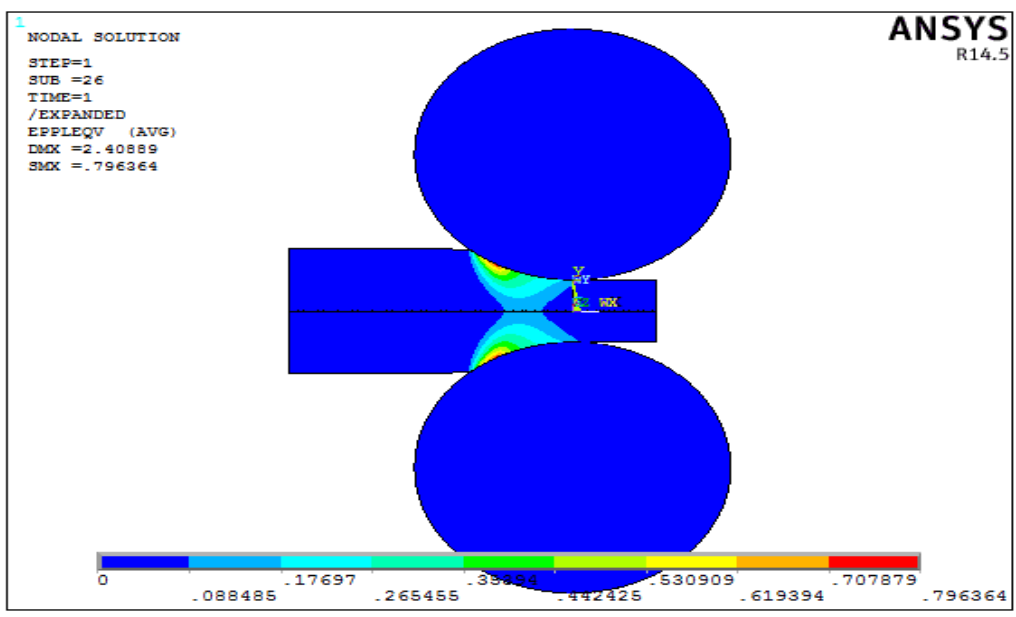

Fig4.28: Plastic Strain Plot (Maximum plastic strain 0.796364)

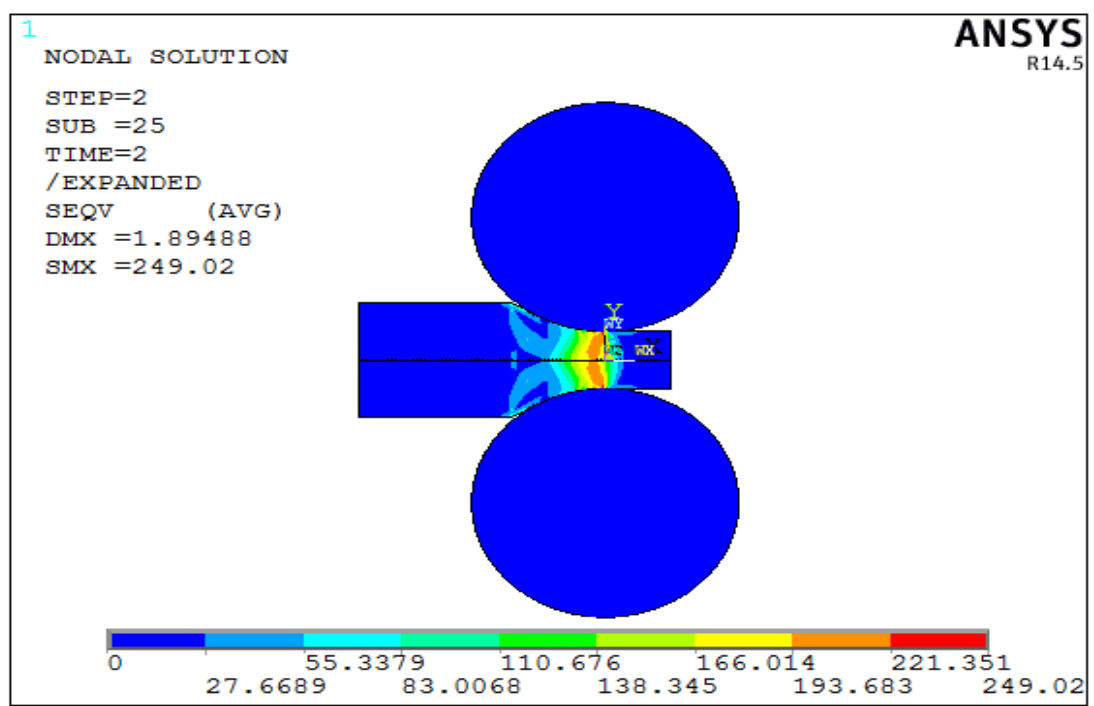

Fig4.30: Vonmises Stress Plot (Maximum vonmises stress 249.02Mpa) 
Table 2: Results comparison for Different diameters of Rollers

\begin{tabular}{|l|l|l|l|}
\hline Diameter of Roller(mm) & Vonmises Stress(Mpa) & Plastic Strain & Contact Pressure(Mpa) \\
\hline 8 & 326 & 1.557 & 560.7 \\
\hline 12 & 323.9 & 1.105 & 487.99 \\
\hline 16 & 320.9 & 0.891 & 451.54 \\
\hline 20 & 319 & 0.796 & 436 \\
\hline
\end{tabular}

The results table 2 shows stress, plastic strain and contact pressure variation with change in the diameter of the roller. The results show reduced value for all vonmises stress, plastic strain and contact pressure which are desirable feature for rolling process. The same thing is proven by the following graphs.

\section{Effect of temperature:}

\section{Result And Discussion}

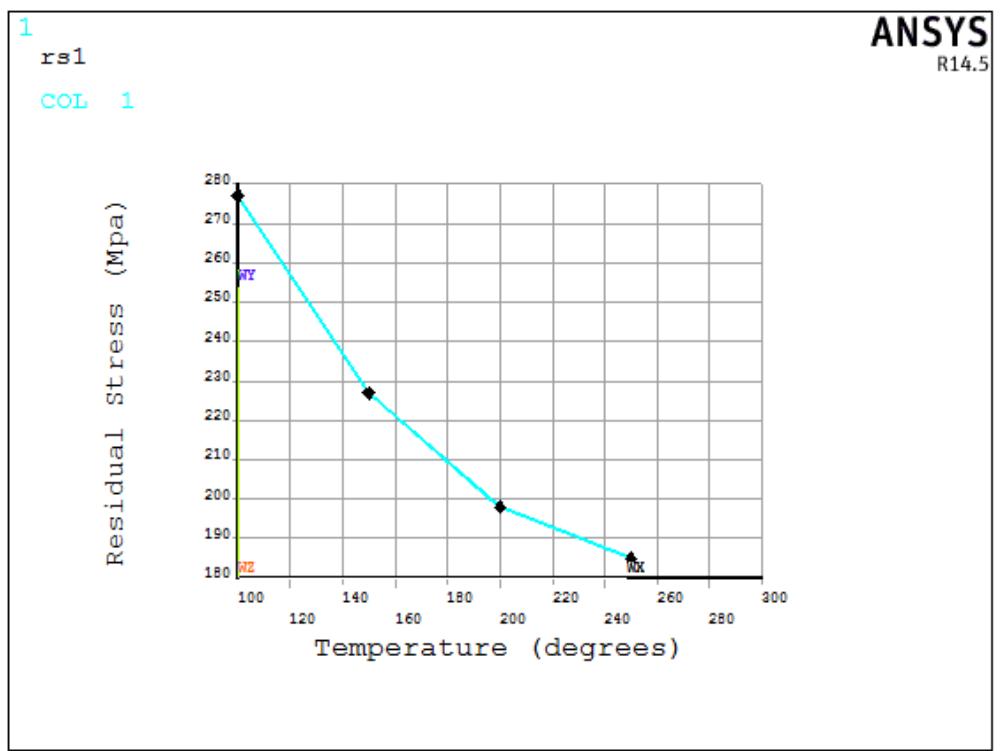

Fig4; Temperature Vs Residual Stress Formation

The figure 4 shows variation of residual stress with the increased temperature values. The drop shows higher temperature reduced the retained residual stress in the structure.

\section{Effect of roller diameters:}

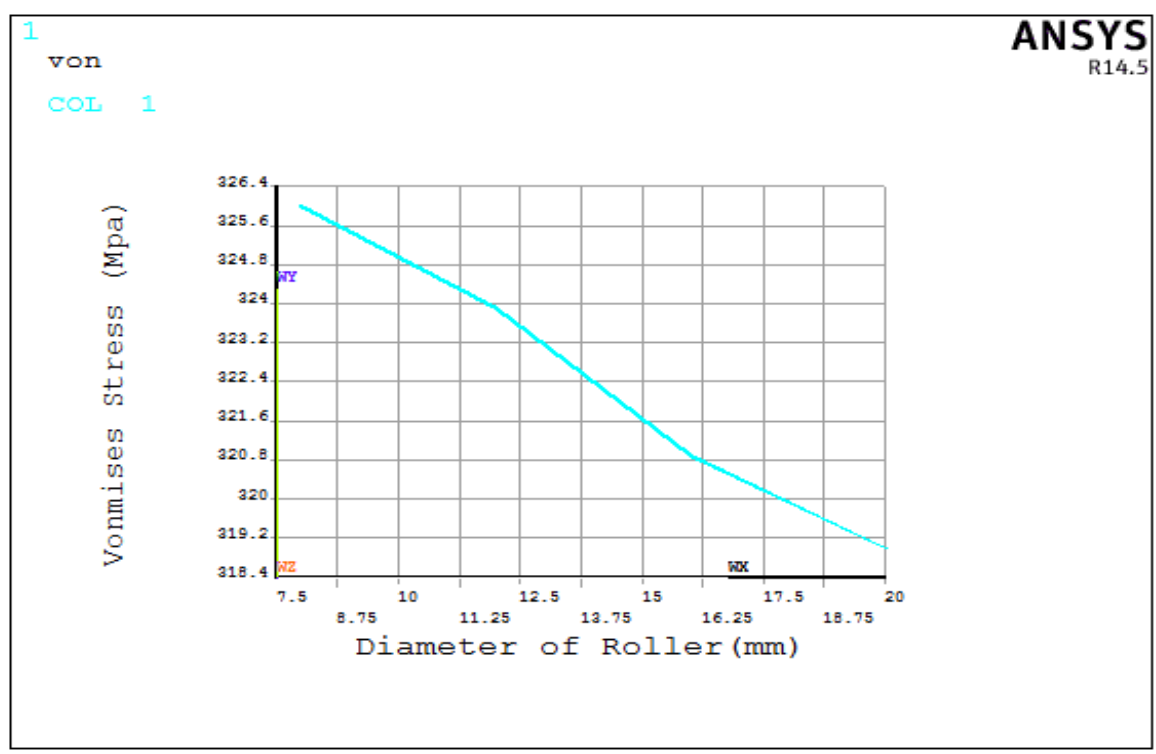

Fig 5: Diameter to Vonmises Stress (Mpa)

The figure shows reduced vonmises stress with the increased roller size. This helps in roller capacity to take more rolling loads. 


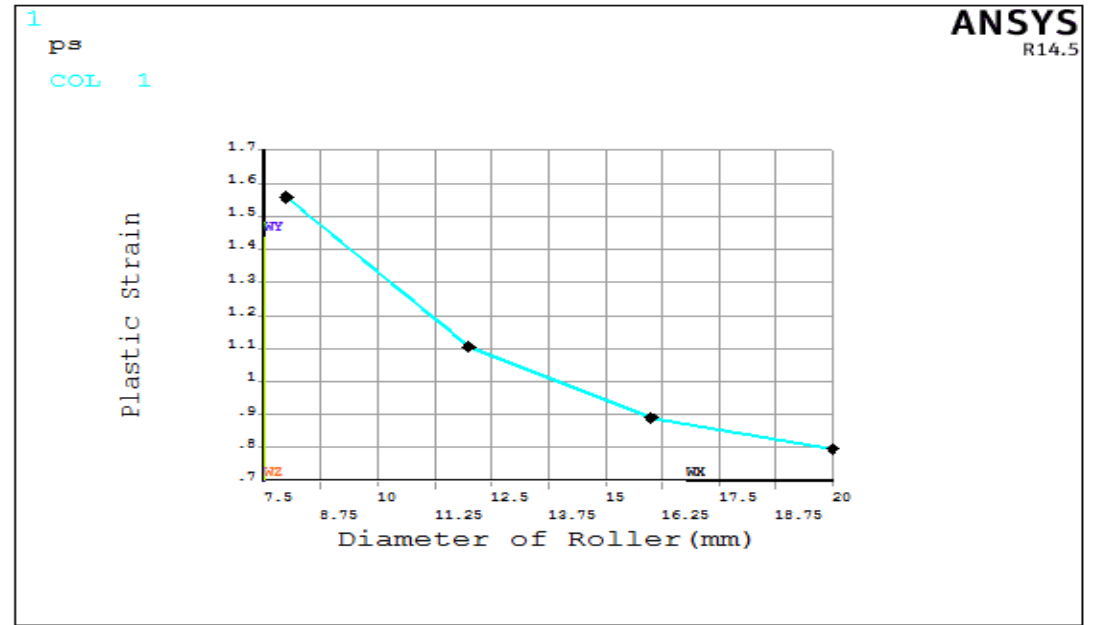

Fig 6: Diameter to Plastic Strain

The figure 6 shows reduced plastic strain with change in the diameter. This is also very important parameter for defect free rolling process. Higher plastic strains are always source of weakness and it can be reduced by higher sized rollers.

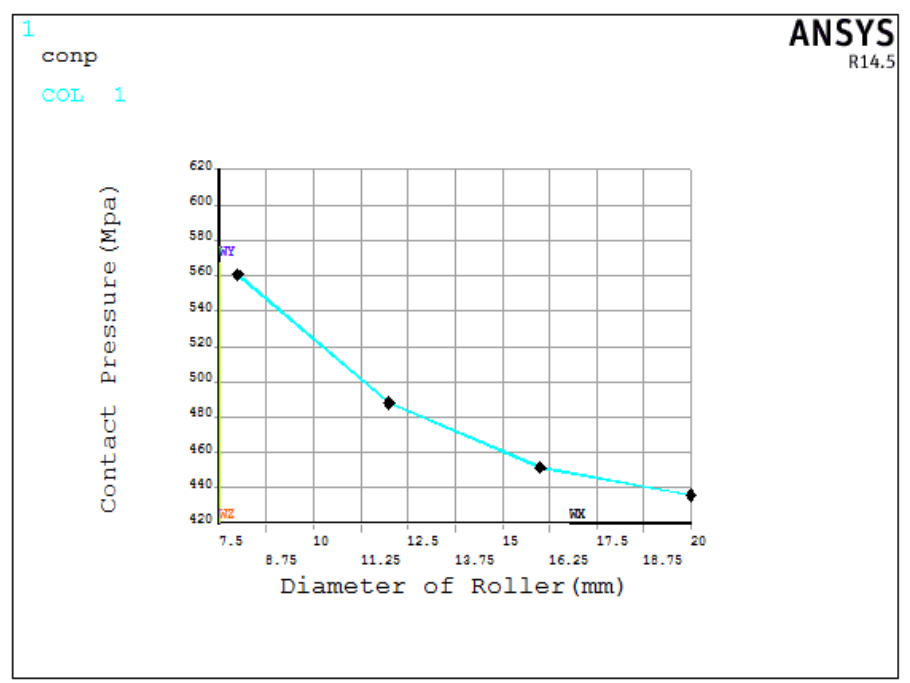

Fig 7: Diameter to Contact Pressure

The contact pressure relation also shows reduced contact pressure with higher diameter rollers. This also important which will reduce the rigidity required for the problem.

\begin{tabular}{|l|l|l|}
\hline Diameter of Roller(mm) & Residual Stress & $\begin{array}{l}\text { Force Requirement(Half } \\
\text { Load) }- \text { N }\end{array}$ \\
\hline 8 & 277 & 54776 \\
\hline 12 & 227 & 61490 \\
\hline 16 & 245 & 67493 \\
\hline 20 & 249 & 72663 \\
\hline
\end{tabular}

Table 3: Comparison of Residual Stress with Force requirements

The table 3 shows increased force requirement with higher sized rollers which is not desirable property for the rollers. Similarly residual stress is not varying in particular path. But the simulation helps in finding the correct size of the rollers for lesser contact pressure, lesser vonmises, less plastic strain and contact pressure. The same pattern is represented by the following graphs. 


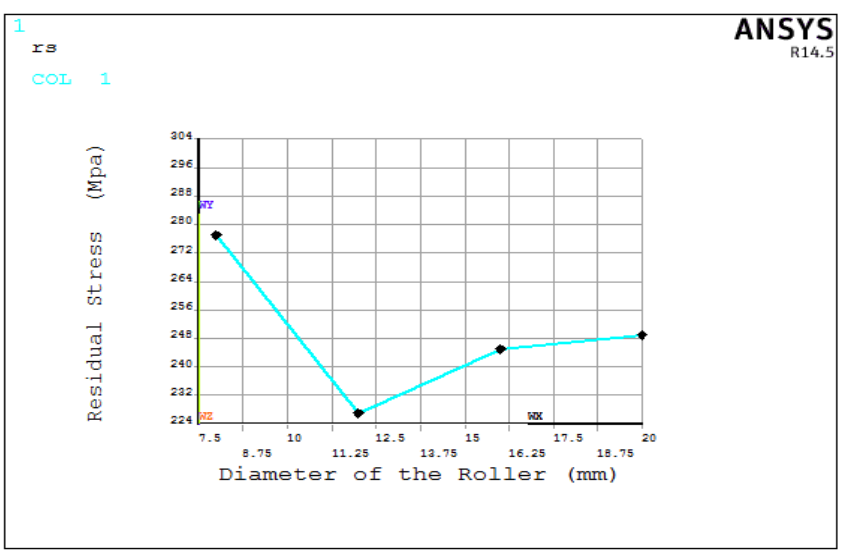

Fig; 8: Roller Diameter to Residual Stress formation

The figure 8 shows variation of residual stress with roller diameter. The graph shows finding the optimum size of roller for given rolling process. A design should have minimum residual stress formation for longer life.

\section{Conclusion}

The rolling simulation has been carried out to find the effect of roller size and thermal effects on the rolling parameters using finite element analysis. The summary of results is as follows.

- Initially the geometry is built for rollers and the sheet metal for rolling using ansys mixed approach.

- Due to symmetry of operation, half geometry is built. The geometry is split to ease map meshing of the structure. Plane 182 element with large deformation effect with plasticity support is considered for the analysis

- Dense mesh is created in the region of mesh and spacing options are used to create graded mesh. Targe169 and contac172 elements with augmented eulerian algorithm are defined between the rigid roller and flexible roller material. Initially the material properties are considered at $100{ }^{\circ} \mathrm{C}$.

- Initially the analysis is carried out with changing the roller size from $8 \mathrm{~mm}$ to $12 \mathrm{~mm}$ with $4 \mathrm{~mm}$ increments. Every time the model is rebuilt and mesh is regenerated with contact elements between the roller and the sheet metal.

- Displacement convergence is considered for the nonlinear material and geometrical nonlinear problem for better results. The results are captured for vonmises, residual stress, and contact pressure and plastic strains.

- The results shows drop in the values for vonmies, contact pressure, plastic strain with the increase in the values of roller size. But the residual stress is varying which indicates using finite element software, the optimum size of roller can be calculated for better product.

- But the force requirements shows increased demands for higher loads with the increase in the size of roller which is not a desirable feature for better rolling system design.

- Further temperature effect on rolling process is analysis. The result shows reduced values for residual stress which is a desirable feature for long lasting rolled products. This can be mainly attributed to reduced yield stress with higher temperatures. Also lesser plastic strain helps in preventing the cracks in the rolled products.

- All the necessary results are represented in the problem.

\section{References}

[1] Residual Stresses in Hot-rolled Solid Round Steel Bars And Their Effect on the Compressive Resistance of Members, YONGCONG DING Windsor University, Windsor, Ontario, and Canada2000,Note that the journal title, volume number and issue number are set in italics.

[2] Rolling mill optimization using an accurate and rapid new model for mill deflection and strip thickness profile ARIF SULTAN MALIK M.S.E., Wright State University, 2001 B.S.M.E., Wright State University, 1994, patent pending application no. US11/686,381.

[3] Simulation of Thermo-mechanical Deformation in High Speed Rolling of Long Steel Products SOUVIK BISWAS September 11, 2003.

[4] Advances in numerical modeling of manufacturing processes: application to steel, aerospace and automotive industries RAJIV SHIVPURI Trans. Indian Inst. Met.Vol.57, No. 4, August 2004, pp. 345-366

[5] About Rolling Conditions in Section Mills DR.-ING. KARL HEINRICH SCHROEDER

[6] Genetic Algorithms in Hot Steel Rolling for Scale Defect Prediction JARNO HAAPAMÄKI AND JUHA RÖNING World Academy of Science, Engineering and Technology 52005

[7] Finite element analysis of cross-wedge rolling ZBIGNIEW PATER

The Arabian Journal for Science and Engineering, Volume 30, Number 1C., 2005 